Autoradiographs of martensite indicate a random distribution of carbon in austenite with no abnormal grain boundary effects. None of the autoradiographs of specimens carburized above the $\alpha$-to- $\gamma$ transformation temperature in pure iron gave any evidence of accelerated grain boundary diffusion of carbon in austenite.

\section{Acknowledgments}

The authors wish to express their appreciation for the helpful discussions with J. E. Willard, Professor of Radio-Chemistry at the University of Wisconsin, and Walter V. Green, Graduate Student at the University of Wisconsin, and for the Nuclear Track Emulsions kindly supplied by Eastman Kodak Co.

\section{References}

J. S. Arnold: An Improved Technique for Liquid Emulsion Autoradiography. Proceedings Soc. for Experimental Biology and Medi-

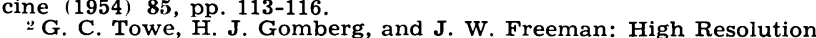
Autoradiography. Technical Note 3209 NACA (July 1954).

Technical Note

\title{
Effect of Cooling Rate on Hardness of Commercial Titanium Alloys
}

by Howard Martens

$\mathbf{H}$ ARDNESS behavior of commercial titanium alloys following various heat treating processes has been studied for some time. However, the hardness of such alloys following a definite measured cooling rate from the single phase $\beta$ region has not been reported. Therefore, a series of experiments was conducted on the three alloys: $150 \mathrm{~A}, 130 \mathrm{~A}$, and $130 \mathrm{~B}$. The manufacturers gave the following compositions for these alloys: $\mathrm{Ti} 150 \mathrm{~A}: 0.045$ pct $\mathrm{C}, 0.069$ pet $\mathrm{N}, 1.32$ pct $\mathrm{Fe}$, and 2.68 pct $\mathrm{Cr}$; RC $130 \mathrm{~A}$ : 0.13 pct $\mathrm{C}$, and 7.9 pet $\mathrm{Mn}$; RC $130 \mathrm{~B}$ : 0.11 pet C, 3.5 pct $\mathrm{Mn}$, and 3.2 pct Al. A method similar to that described by Greninger ${ }^{1}$ was used, and the cooling rate varied from $6^{\circ}$ to $9200^{\circ} \mathrm{F}$ per sec. The cooling curves were recorded on a Speedomax or a recording oscillograph, and the hardness was measured on a Tukon hardness tester using a Knoop indentor with a 500 g load.

The curves of Fig. 1 show the variation of the Knoop hardness with the cooling rate for these three alloys. The alloys $150 \mathrm{~A}$ and $130 \mathrm{~B}$ behave in a similar manner, as shown by the curves. In neither of these alloys was it possible to retain the high temperature $\beta$ phases, even by the most rapid cooling rate. The slow cooling rates produced a typical $\alpha+\beta$ structure in these two alloys. As the cooling was increased, these phases became more finely dispersed and the hardness increased. This increase in hardness with cooling rate continued for the $150 \mathrm{~A}$ alloy until a rate of approximately $1000^{\circ} \mathrm{F}$ per sec was reached. At this cooling rate, the structure showed the result of the diffusionless transformation of the $\beta$ solid solution to the supersaturated $\alpha$ solid solution which is referred to as $\alpha^{\prime}$. At higher cooling rates, the structure showed no change and the hardness showed no great change, as indicated by the dotted portion of the curve in Fig. 1. The increase in hardness with cooling rate for the $130 \mathrm{~B}$ alloy continued until a rate of approximately $300^{\circ} \mathrm{F}$ per sec was reached. At this rate the $\alpha^{\prime}$ structure was produced and the maximum hardness was reached. Higher cooling rates caused no marked changes in hardness or structure.

The alloy 130A behaved in a different manner, as shown by the curve of Fig. 1. The structure produced by the slow cooling rates was a typical $\alpha+\beta$ structure, which became finely dispersed as the cooling rate increased. The hardness increased with

H. MARTENS is Research Engineer, Jet Propulsion Laboratory, California Institute of Technology, Pasadena, Calif.

TN 292E. Manuscript, June 27, 1955.
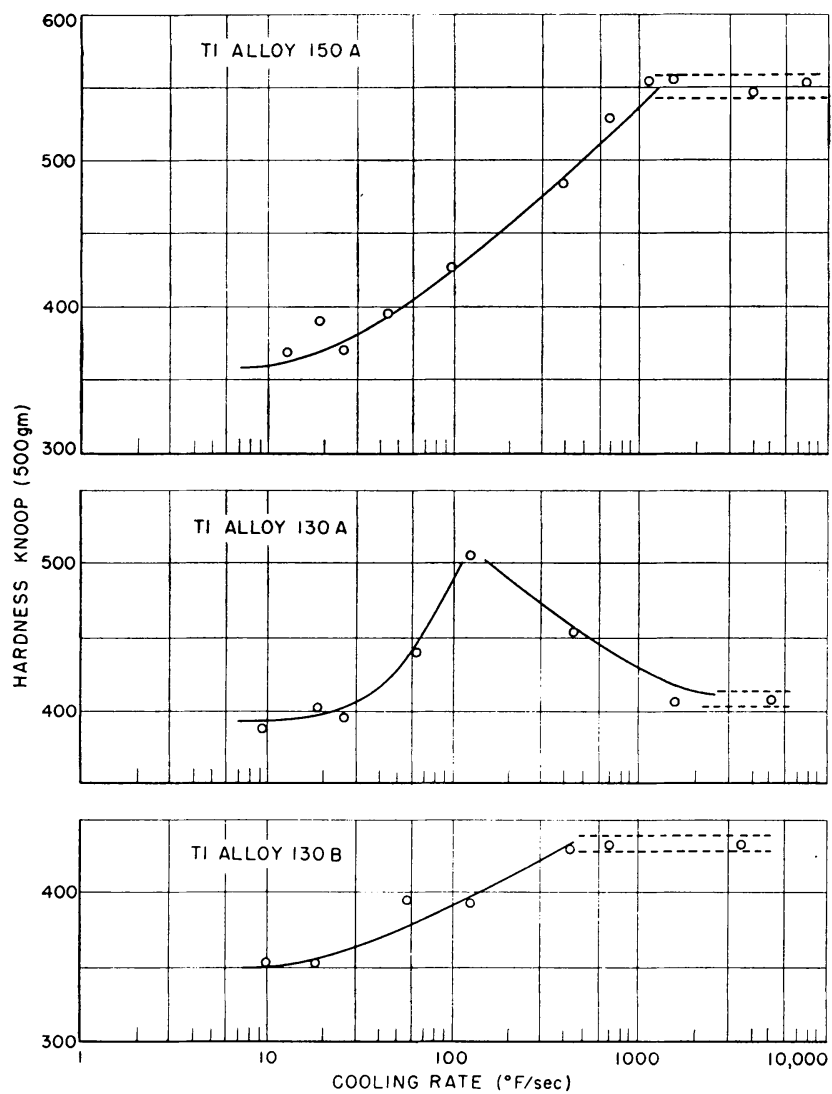

Fig. 1-Curves show the variation of Knoop hardness with cooling rates from $2000^{\circ} \mathrm{F}$ for alloys Ti 150A, RC 130A, and RC $130 \mathrm{~B}$.

cooling rate and reached a maximum at approximately $120^{\circ} \mathrm{F}$ per sec. At this maximum hardness, the structure showed the result of the decomposition of the $\beta$ phase into the $\beta+\omega$ phase structure. As the cooling rate was increased, smaller amounts of the $\omega$ phase were formed and the alloy became softer. For cooling rates of $3000^{\circ} \mathrm{F}$ per sec and above, the high temperature $\beta$ phase was retained and the hardness of the alloy did not change markedly.

\section{Acknowledgment}

This paper presents the results of one phase of research carried out at the Jet Propulsion Laboratory, California Institute of Technology, under Contract No. DA-04-495-Ord 18, sponsored by the Dept. of the Army, Ordnance Corps.

1 A. B. Greninger: The Martensite Thermal Arrest in Iron-Carbon Alloys and Plain Carbon Steels. Trans. ASM (1942) 30, pp. 1-26. 